\title{
THE STUDY, CLINICAL IMPLICATIONS AND SOLUTIONS FOR FAILED VARICOSE VEIN SURGERY WITH RECURRENT VENOUS ULCERS: AN ANALYSIS OF 12 PATIENTS WITH DUPLEX SCAN CORRELATED WITH INTRA OPERATIVE FINDINGS AT SECOND SURGERY
}

\author{
Gopinath H. Venkatarao', Nanda Kishore K. Lahoti²
}

${ }^{1}$ Assistant Professor, Department of General Surgery, Subbaiah Institute of Medical Sciences, Purale, Shimoga, Karnataka. 2 Professor and Vascular Surgeon, Department of General Surgery, Subbaiah Institute of Medical Sciences, Purale, Shimoga, Karnataka.

\section{ABSTRACT}

\section{BACKGROUND}

Venous ulcer is an under-recognized and under-treated disease and it affects quality of life. Chronicity and recurrence is disappointing finding, both for the patient and surgeon.

\section{AIM}

To study any surgically correctable factors in recurrent venous ulcers and clinical implications and to offer solutions that prevent or reduce failure rate of primary surgery in the management of venous ulcers.

\section{MATERIALS AND METHODS}

12 patients with recurrent venous ulcers following previous procedures for varicose veins were enrolled in this study. Full detailed history, examination and investigations were done.

\section{RESULTS}

Out of 12 patients with recurrent venous ulcers, 10 (83\%) had undergone saphenofemoral junction ligation and stripping, $2(16 \%)$ had undergone laser ablation (Endovenous laser ablation), all had perforator ligation, 7 had undergone split skin grafting with ulcer recurrence, none had Saphenopopliteal junction ligation. When all patients were re-evaluated, we found that 5 patients had incompetent saphenofemoral junction, 2 of them in endovenous laser ablation group; 5 out of 12 had Saphenopopliteal junction incompetency. All 12 patients had incompetent perforators. All 12 of them underwent corrective surgery. All were followed up for 6 months to 36 months (Mean=25.5 months) with ulcers showing complete healing with no further evidence of breakdown during follow-up.

\section{CONCLUSION}

Surgery is recommended for venous ulcer patients in all stages. Preventable surgical errors are to be excluded for recurrent venous ulcers. Careful evaluation and accurate preoperative mapping of venous pathology with the help of sonologist experienced in vascular study. Role of surgeon experienced with vascular surgery will prevent failure rate.

\section{KEYWORDS}

Venous Ulcers, Failed Procedures, Redo Surgery.

HOW TO CITE THIS ARTICLE: Venkatarao GH, Lahoti NKK. The study, clinical implications and solutions for failed varicose vein surgery with recurrent venous ulcers: an analysis of 12 patients with duplex scan correlated with intraoperative findings at second surgery. J. Evolution Med. Dent. Sci. 2016;5(38):2303-2306, DOI: 10.14260/jemds/2016/535

\section{INTRODUCTION}

Venous leg ulcers are the most serious type of chronic venous incompetence.[1] Chronic venous leg ulceration affects $1-2 \%$ population, often with a protracted course of delayed healing and multiple recurrences.[2] Ulcer aetiology is often multifactorial, but the arterial component can safely be ignored in legs with an Ankle-Brachial Pressures Index (ABPI) greater than 0.8.[2],[3] Various methods such as compression treatment, wound dressing materials and surgical modalities are used for venous leg ulcer therapy.[4]

Financial or Other, Competing Interest: None.

Submission 17-02-2016, Peer Review 01-03-2016,

Acceptance 04-03-2016, Published 11-05-2016.

Corresponding Author:

Dr. Gopinath H. Venkatarao,

No. 49, Vaishnavi, Ground Floor,

Near Water Tank Behind Shivalaya Temple,

100 Feet Road, Vinoba Nagar,

1st Phase, Shimoga-577204,

Karnataka, India

E-mail: hvgnath@gmail.com

DOI: 10.14260/jemds/2016/535
Recurrence may be due to several causes: inaccurate initial diagnosis, progression of disease, inadequate initial surgery, altered venous dynamics and neovascularization are some of the factors.[5] Recurrence has been attributed to neovascularization in the granulation tissue around stump of great or short saphenous veins.[6] or to the development of incompetence in pre-existing collateral, which had not been adequately ligated by the previous surgeon.[7]

Attention to technical details will decrease the regrettably high rate of recurrence after saphenofemoral disconnection and render safer exploration. Early postsurgical recurrence results from an incomplete operation, late recurrence after correct surgery is due to deterioration of the remaining superficial venous system or in case of inappropriate surgery.[5] The ultrasonic marker of recurrent lower limb varicose veins was the re-emergence of dilated saphenous and perforating veins as well as valve apparatus failure in the operated leg. Ultrasound study is the most rational method for screening diagnosis in case of abnormal veins of the lower extremities in the postoperative period. ${ }^{[8]}$ 
The aim of this study was to identify the possible causes and patterns of recurrent varicose vein with venous ulcers of lower limbs in patients with history of varicose veins surgery and other procedures and to explore clinical implications and solutions.

\section{METHODS}

Between August 2012 to August 2015, 12 patients with 12 legs were presented with currently active venous ulcers (CEAPC6), defined as epithelial discontinuity of at least 4-week duration and with a history of having undergone various procedures like (a) Surgical interruption of superficial venous system and perforator veins incompetence including laser ablation, and (b) Surgical procedure for ulcer itself (e.g.: Split skin grafting) were studied.

All 12 patients were evaluated with past medical and surgical history and clinical examination of vascular system and Ankle Brachial Pressure Index (ABI). The venous function was measured with duplex scan (Colour Doppler) and preop mapping of superficial venous system and incompetent perforators with the help of a Sonologist, experienced with study of vascular disorders. Ulcerated legs were clinically assessed with both ABPI and colour venous duplex studies being performed.[9] The following venous segments were insonated in all patients: common and superficial femoral veins, popliteal vein, sapheno-femoral junction, long saphenous vein and major tributaries, sapheno-popliteal junction, short saphenous vein, thigh and calf perforating veins.

Deep calf veins were also assessed. The ulcer area was also imaged, being protected from the probe by cling-film to assess any local variations in reflux pattern. Perforator vein incompetence was designated as superficial venous reflux. Reflux was defined as significant if longer than $1 \mathrm{~s}$ duration following manual calf compression and release. "Pathologic" perforating veins includes those with an outward flow of duration of $500 \mathrm{~ms}$ with a diameter of $3.5 \mathrm{~mm}$ and a location beneath healed or open venous ulcers (CEAP Class C5-C6).[9] Patients with leg ulcers associated with deep venous insufficiency, post thrombotic legs and peripheral vascular disease were excluded from this study.

All patients were initially optimized with cessation of smoking, correction of anaemia, control of diabetes mellitus, control of wound infection, control of hypertension and hypercholesterolemia other than compression bandaging for venous ulcers.

The goal was to abolish venous refluxes in the superficial and perforating veins as detected and marked by duplex scan to reduce venous hypertension in the affected area or the entire leg. To accomplish this goal surgery of the great saphenous vein, the short saphenous vein and/or surgery of the perforator veins was performed. No surgery of deep veins was performed. No venous anomaly or neovascularization were noted. All 12 patients underwent corrective surgery (Table 5) and post-operatively continued with compression bandaging for venous ulcers for 4-6 weeks with 3 monthly follow-up ranging from 8 months to 36 months with signs of ulcer healing. Ulcer healing was defined as full reepithelialisation with absence of secretions and recurrence as epithelial breakdown in the ipsilateral healed limb. Time to healing was calculated from the initial assessment and duplex scan date.
Time to recurrence was during the 6 months prior to presentation, calculated from the date of ulcer healing or date of initial assessment for recently healed legs. An analysis of intraoperative findings correlated with duplex scan findings has been presented.

\section{RESULTS}

\section{Statistical Analysis}

Data entry and analysis were accomplished using windows operating system and the based statistics program (SPSS 10.0) adopting in the outcome the following statistical tests: 1 . Continuous variables are expressed as means, 2. Discrete variables are expressed as frequencies and percentages, 3 . Presentation of the statistical outcome in the form of tabulation and were accomplished by windows based Microsoft Excel.

All patients were males and their age distribution was shown in table.(1) All patients are from lower socio-economical class and had jobs that demanded prolonged standing during their work that had affected ulcer healing and quality of life. Prolonged standing is one of the main factors, which can precipitate varicose veins and it is also one of the main factors of recurrence due to increase venous pressure, especially in diseased venous valves (Table 2). Other risk factors and comorbidity were presented in table.(3)

Relationship between the previous operations performed and the post-operative recurrence range from 1-10 years with mean of 5.5 years. Table ( 3 and 4 ). Some patients had undergone multiple procedures at multiple times and centres before reporting to us.

All patients underwent preoperative evaluation with Duplex Scan that showed following surprise findings. Tables. (5) These findings matched intraoperative findings. Out of 12 patients with recurrent venous ulcers, 10 (83\%) had undergone saphenofemoral junction ligation and stripping, $2(16 \%)$ had undergone endovenous laser ablation. All had perforator ligation; 7 patients had undergone skin grafting with ulcer recurrence. None had saphenopopliteal junction surgery. When all patients were re-evaluated with duplex scan, we found that $5(41.6 \%)$ patients had incompetent SFJ, 2 of them in endovenous laser ablation group; 5 out of 12 (41.6\%) had saphenopopliteal junction incompetency.

All had incompetent perforators. All of them underwent corrective surgery (Table 5). No venous anomaly or neovascularization were noted in the previous surgery site. Wrong site of incision containing excess fat leading to missed persistent incompetent saphenofemoral junction of the superficial system in the groin in 3 patients was observed. All were followed up for 8 months to 36 months (Mean=25.5 months) with ulcers showing complete healing with no further evidence of breakdown during follow-up.

\begin{tabular}{|c|c|c|}
\hline Age Group & No. & \% \\
\hline $30-39$ & 2 & 16 \\
\hline $40-49$ & 5 & 41.6 \\
\hline $49-60$ & 5 & 41.6 \\
\hline Total & $\mathbf{1 2}$ & $\mathbf{1 0 0}$ \\
\hline Mean age & 46.7 & \\
\hline \multicolumn{2}{|c|}{ Table 1: Age Distribution in the Study Group } \\
\hline
\end{tabular}




\begin{tabular}{|c|c|}
\hline Occupation & No. \\
\hline Agriculturist & 4 \\
\hline Security Guard & 2 \\
\hline Factory Worker & 2 \\
\hline Food Canteen Worker & 1 \\
\hline Teacher & 2 \\
\hline Driver & 1 \\
\hline Total & $\mathbf{1 2}$ \\
\hline \multicolumn{2}{|c|}{ Table 2: Occupation Data } \\
\hline
\end{tabular}

\begin{tabular}{|c|c|}
\hline Risk Factors & No. \\
\hline Mean age & 46.7 years \\
\hline Gender & M=12 \\
\hline $\begin{array}{c}\text { Mean ulcer duration from previous } \\
\text { procedure }\end{array}$ & 5.5 years \\
\hline $\begin{array}{c}\text { Occupation history requiring } \\
\text { standing for long time }\end{array}$ & 12 \\
\hline Smoking history & 2 \\
\hline Anaemia & 2 \\
\hline DM & 5 \\
\hline Hypertension & 3 \\
\hline Hypercholesterolemia & 2 \\
\hline
\end{tabular}

Table 3: Demographic Variables and Risk Factors in this Study Group of 12 Patients

\begin{tabular}{|c|c|c|}
\hline Duration & & $\%$ \\
\hline Less than 2 years & 2 & 16.6 \\
\hline $2-5$ years & 3 & 25 \\
\hline 6-10 years & 7 & 58.3 \\
\hline Total & 12 & 100 \\
\hline Mean & 5.5 & \\
\hline \multicolumn{3}{|c|}{ Table 4: Duration of Ulcers after Previous Procedure } \\
\hline
\end{tabular}

\begin{tabular}{|c|c|c|c|c|}
\hline $\begin{array}{c}\text { Previous } \\
\text { Surgery } \\
\text { Group }\end{array}$ & $\begin{array}{c}\text { Duplex } \\
\text { Scan and } \\
\text { Intraop } \\
\text { Findings }\end{array}$ & $\%$ & $\begin{array}{c}\text { Second } \\
\text { Surgery } \\
\text { Performed }\end{array}$ & $\begin{array}{c}\text { Any } \\
\text { Venous } \\
\text { Anomaly }\end{array}$ \\
\hline $\begin{array}{c}\text { SFJ } \\
\text { ligation } \\
\text { group }\end{array}$ & $\begin{array}{c}\text { Persistent } \\
\text { incompetent } \\
\text { SFJ }\end{array}$ & & $\begin{array}{c}\text { SFJ ligation } \\
\text { only }\end{array}$ & nil \\
\hline 10 & 3 & 30 & 3 & \\
\hline $\begin{array}{c}\text { Laser } \\
\text { ablation } \\
\text { group }\end{array}$ & $\begin{array}{c}\text { Persistent } \\
\text { incompetent } \\
\text { SFJ }\end{array}$ & & $\begin{array}{c}\text { SFJ ligation } \\
\text { only }\end{array}$ & nil \\
\hline 2 & 2 & 100 & 2 & \\
\hline Total-12 & \multicolumn{5}{|c|}{5} & 41.6 & 5 & \\
\hline \multicolumn{5}{|c|}{ Table 5: Duplex and Intraop Findings } \\
Affecting Ulcer Healing in the Study \\
\hline \multicolumn{5}{|c|}{} \\
\hline
\end{tabular}

\begin{tabular}{|c|c|c|}
\hline $\begin{array}{c}\text { Previous } \\
\text { Gurgery } \\
\text { Group }\end{array}$ & $\begin{array}{c}\text { Duplex Scan and } \\
\text { Intraop Findings at } \\
\text { Second Surgery No. of } \\
\text { Patients with } \\
\text { Incompetence }\end{array}$ & $\begin{array}{c}\text { Second } \\
\text { Surgery } \\
\text { Performed }\end{array}$ \\
\hline $\begin{array}{c}\text { SPJ } \\
\text { Incompeten } \\
\text { ce Group }\end{array}$ & Incompetent SPJ & SPJ ligation \\
\hline 0 & 5 & 5 \\
\hline $\begin{array}{c}\text { Perforator } \\
\text { incompeten } \\
\text { ce surgery } \\
\text { group }\end{array}$ & $\begin{array}{c}\text { At scar and at new places } \\
>3.5 \mathrm{~mm}\end{array}$ & $\begin{array}{c}\text { Subfascial } \\
\text { Ligation }\end{array}$ \\
\hline 7 & 12 & \\
\hline
\end{tabular}

\begin{tabular}{|c|c|}
\hline Previous Surgery Group & Second Surgery Performed \\
\hline SSG group & nil \\
\hline 7 & \\
\hline
\end{tabular}

\section{DISCUSSION}

\section{Clinical Implications}

Some evidence suggests that surgical treatment methods may lead to greater improvements in patient's quality of life than compression bandaging alone.[10] This study has demonstrated that venous ulcers recur due to various demographic and aetiological factors and not so surprisingly following inaccurate initial diagnosis, progression of disease or inadequate initial surgery, wrong site of incision containing excess fat leading to missed persistent incompetent saphenofemoral junction.[5] Surgical treatment of superficial axial and perforator vein reflux speeds healing and reduces recurrence. Missed persistent incompetent saphenofemoral junction was observed in 3 patients from our study who underwent redo saphenofemoral junction flush ligation. [5]

Currently available evidence suggests there is little to choose between the minimally invasive techniques in terms of efficacy or cost and each offers a viable, clinically effective alternative to stripping.[11] Venous ulcer could be satisfactory treated by the total removal of the periulcer reflux.[12] Correction of reflux of the superficial and perforator system remains useful even with the advent of endovenous laser treatment. Anatomical failures are known to occur in endovenous laser ablation and radiofrequency ablation.[13] Following saphenous ablation duplex ultrasound can show procedural failure, but some of these patients have clinical improvement that is maintained long-term. Anatomic failure is a useful term to distinguish these patients from those with clinical failure (i.e. recurrent clinical symptoms and/or varicose veins).

\section{Anatomic Failure has been Classified as Follows}

- Non-occlusion - Type I anatomic failure refers to veins that failed to occlude initially and never occlude during followup.

- Recanalization - Type II anatomic failure refers to veins that were initially confirmed to be occluded, but later recanalize, either partially or completely.

- Groin Reflux - Type III anatomic failure refers to the situation in which the vein trunk was occluded, but reflux persisted in the groin region. This type of failure often involves an accessory saphenous vein.

Type III anatomic failure was found in 2 patients from this study, but without accessory saphenous vein and was treated with saphenofemoral junction flush ligation.

In this study, all patients underwent open perforator ligation. One study states that only $12 \%$ of perforators were suitable for treatment with Subfascial Endoscopic Perforator Surgery (SEPS), especially in cases of more than one perforator.

Subfascial Endoscopic Perforator Surgery (SEPS) should be considered a minimized approach compared with other surgical techniques and is often not useful if there is only one perforator.

In our study, all ulcers healed including previously skin grafted ones without any additional procedures. In one study, skin graft is necessary only for big and/or deep ulcers. In cases 
of small and superficial ulcers, shaving with a scalpel or a sharp spoon can impede self-healing without a graft. In cases of large ulcers combined with induration or calcification, fasciectomy should be performed to remove the defect and help facilitate short healing times.

There are very few epidemiological data available related specifically to recurrent venous ulcers in relationship to previous various procedures. Other studies have shown one year recurrence of $25 \%$ and 3 year recurrence of $38 \%$.[14][15] Previous studies have failed to show a benefit from superficial venous surgery in terms of haemodynamic change or ulcer healing in patients with mixed deep and superficial reflux.[16] They had included primary varicose ulcer procedures and ulcers associated with deep venous insufficiency and postthrombotic legs. This is a limited study in number because patients were selected for failed procedures with exclusion of primary varicose ulcer procedures and ulcers associated with deep venous insufficiency and post-thrombotic legs. Post procedure follow-up for healing rate is also short, but with a good short term result of $100 \%$, no recurrence for 3 years with a mean of 25.5 months.

\section{CONCLUSIONS}

There is no universal methods to treat venous ulcer. Chronic venous leg ulcers benefit from surgery. Surgical treatment of superficial axial and perforator vein reflux speeds healing and reduces recurrence.[17] The recurrence is an avoidable complication of an imperfect primary surgery.[18] A surgeon with expertise in venous surgery and accurate preoperative Duplex ultrasound assessment is important. These two factors lead to true diagnosis or false one as assessment of incompetent valves at the saphenofemoral and saphenopopliteal junctions and the perforators and also the patency of the deep venous system and absence of thrombosis. This will prevent failed varicose surgeries with recurrent ulcerations. Even though endovenous laser treatment is an advance in the minimized surgical approach, it can never fully displace accepted surgical procedures. ${ }^{[15]}$ Anatomical failures are to be recognized in endovenous ablations procedures and should be combined with open surgery.

\section{REFERENCES}

1. Porter JM, Moneta GL. Reporting standards in venous disease: an update. International consensus committee on chronic venous disease. J Vasc Surg 1995;21:635-45.

2. Moffatt CJ, Franks PJ, Oldroyd M, et al. Community clinics for leg ulcers and impact on healing. BMJ 1992;305:13891392.

3. Blair SD, Wright DDI, Backhouse CM, et al. Sustained compression and healing of chronic venous ulcers. BMJ 1988;297:1159-1161.

4. Gallenkemper G, Bulling BJ, Kahle B, et al. Leitlinien zur diagnostik und therapie des ulcus cruris venosum. Phlebologie 1996;25:254-8.

5. Allaf N, Welch M. Recurrent varicose veins: inadequate surgery remains a problem. Phlebology 2005;20:138-40.

6. Geier B, Olbrich S, Barbera L, et al. Validity of the macroscopic identification of neovascularization at the saphenofemoral junction by the operating surgeon. J Vasc Surg 2005;41:64-8.
7. Creton D. Surgery for recurrent saphenofemoral incompetence using expanded polytetrafluoroethylene patch interposition in front of the femoral vein: long-term outcome in extremities. Phlebology 2002;16:93-7.

8. Tatarchuk AN. Capacities of ultrasound study in a follow up of patients with lower extremity varicose veins after phlebectomy. Vestn Rentgenol Radiol 2011;1:22-5.

9. Campbell WB, Halim AS, Aertssen A, et al. The place of duplex scanning for varicose veins and common venous problems. Ann R Coll Surg Engl 1996;78:490-493.

10. Tollow P, Ogden J, Whiteley MS. The comparative impact of conservative treatment versus superficial venous surgery, for the treatment of venous leg ulcers: a systematic review of the impact on patients' quality of life. Phlebology 2015 Apr 8, pii: 0268355515581278, 2016;31(2):82-93.

11. Carroll C, Hummel S, Leaviss J, et al. Clinical effectiveness and cost-effectiveness of minimally invasive techniques to manage varicose veins: a systematic review and economic evaluation. Health Technol Assess 2013;17(48):1-141.

12. Kanchanabat B, Stapanavatr W, Kanchanasuttiruk P. Total superficial vein reflux eradication in the treatment of venous ulcer. World J Surg 2015;39(5):1301-5. doi: 10.1007/s00268-014-2935-y.

13. Khilnani NM, Grassi CJ, Kundu S, et al. Multi-society consensus quality improvement guidelines for the treatment of lower-extremity superficial venous insufficiency with endovenous thermal ablation from the society of interventional radiology, cardiovascular interventional radiological society of Europe, American college of phlebology and Canadian interventional radiology association. J Vasc Interv Radiol 2010;21(1):14.

14. Gloviczki P, Comerota AJ, Dalsing MC, et al, The care of patients with varicose veins and associated chronic venous diseases: clinical practice guidelines of the society for vascular surgery and the American venous forum. Official publication: The society for vascular surgery and international society for cardiovascular surgery, North American, chapter May. Article in journal of vascular surgery 2011.

15. Obermayer A, Göstl K, Walli G, et al. Chronic venous leg ulcers benefit from surgery: long-term results from 173 legs. J Vasc Surg 2006;44(3):572-9.

16. Erickson CA, Lanza DJ, Karp DL, et al. Healing of venous ulcers in an ambulatory care program: the roles of chronic venous insufficiency and patient compliance. J Vasc Surg 1995;22:629-36.

17. Scriven JM, Hartshorne T, Thrush AJ, et al. Role of saphenous vein surgery in the treatment of venous ulceration. Br J Surg 1998;85:781-784.

18. Pourhassan S, Zarras K, Mackrodt HG, et al. Recurrent varicose veins. Surgical procedure-results. Zentralbl Chir 2001;126:522-5. 